\title{
Antizyme is necessary for conversion of pancreatic tumor cells into glucagon- producing differentiated cells
}

\author{
Jun-ichiro Suzuki, Yasuko Murakami, Keijiro Samejima, Kohfuku Kohda \\ Masahiro Ohtani and Takami Oka
}

Faculty of Pharmacy, Musashino University, 1-1-20 Shin-machi, Nishitokyo-shi, Tokyo 202-8585, Japan

(Correspondence should be addressed to T Oka; Email: toka@musashino-u.ac.jp)

\begin{abstract}
Human pancreatic tumor cell lines - AsPC-1, PANC-1, MIA paca2, KP-1 and KP-59 cells can be induced to differentiate into pancreatic hormone-producing cells by brief trypsin treatment and subsequent culture in a serum-free, chemically defined medium. During culture, AsPC-1 cells formed cell clusters resembling the pancreatic islets, expressed genes associated with the pancreatic development and produced glucagon but not insulin. When PANC-1, MIA paca2, KP-1 and KP-59 cells were treated and cultured the same way, they underwent similar morphological changes and produced insulin and glucagon. We used these systems to identify intracellular regulatory molecules involved in the conversion of pancreatic tumor cells into glucagon-producing cells. We found that the expression of antizyme 1 (AZ1), a negative regulator of ornithine decarboxylase, was increased and its localization was altered from the nucleus to the cytoplasm during AsPC-1 cell differentiation. Transient transfection of AsPC-1 cells with AZ1 siRNA resulted in inhibition of the morphological and functional cell differentiation as well as the specific suppression of AZ1 expression. By contrast, constitutive overexpression of AZ1 in AsPC-1 cells led to the enhancement of glucagon production. We also found that PANC-1 cells reduced the expression of glucagon mRNA when treated with AZ1 siRNA. These results suggested that AZ1 was necessary for the conversion of pancreatic tumor cells into glucagon-producing cells. Glucagon production in AsPC-1 cells was not affected by addition of putrescine, suggesting that the polyamines were not directly involved in the AZ1-mediated conversion of pancreatic tumor cells to differentiated state.
\end{abstract}

Endocrine-Related Cancer (2009) 16 649-659

\section{Introduction}

Alpha cell differentiation and glucagon gene expression are mediated by multiple transcriptional factors including Pax6 (St-Onge et al. 1997), ISL1 (Wang \& Drucker 1995), Cdx-2/3 (Andersen et al. 1999, Ritz-Laser et al. 1999), Mafs (Artner et al. 2006), BRN-4 (Hussain et al. 2002), and Foxa-2 (Lee et al. 2005). Pax6 has been shown to interact with $\mathrm{Cdx}-2 / 3$, c-Maf and Maf-B, and mediate the synergistic transactivation of the glucagon gene (Planque et al. 2001, Gosmain et al. 2007). POU3F4 and Foxa-2 have also been shown to activate glucagon gene expression and $\alpha$-cell differentiation. Glucagon is derived from proglucagon, an $18-\mathrm{kDa}$ protein which contains glucagon and two related peptide sequences, glucagon-like peptides 1 and 2 (GLP1 and -2). The proglucagon molecule is processed by prohormone convertase 2 (PC2) in the pancreatic $\alpha$-cells. Hormones processed by PC 2 influence the processes that regulate $\alpha$-cell differentiation and maturation (Vincent et al. 2003). At the present time, however, our understanding of the regulatory mechanism involved in $\alpha$-cell differentiation is still incomplete, and thus requires further studies.

The polyamines including putrescine, spermidine and spermine play a crucial role in cell proliferation 
and functional differentiation by influencing gene expression and protein synthesis (Pegg \& McCann 1982, Tabor \& Tabor 1984). Spermidine and spermine are present at high concentrations in the pancreatic islets (Hougaard et al. 1986). Both putrescine and spermidine are necessary for the maintenance of normal level of insulin biosynthesis in $\beta$-cells (Welsh \& Sjöholm 1988). The polyamine synthesis is regulated negatively by antizyme 1 (AZ1) that binds to ornithine decarboxylase (ODC) and facilitates its degradation (Hayashi et al. 1996, Coffino 2001). AZ1 has a wide tissue distribution and has been implicated to play a role in various cellular functions through its influence on polyamine metabolism (Hayashi et al. 1996, Coffino 2001). The synthesis of AZ1 protein is mediated by a polyamine-dependent mechanism involving a programmed +1 frameshifting during translation of the $A Z 1$ mRNA (Matsufuji et al. 1995, Ivanov et al. 2000). Recent studies have shown that AZ1 also binds to several other proteins including cyclin D1, a cell cycle regulatory protein (Newman et al. 2004), Aurora-A, a mitosis regulatory protein (Lim \& Gopalan 2007), and Smad1 (Gruendler et al. 2001, Lin et al. 2002, Xu et al. 2003). At present, however, the cellular function of AZ1 and its relationship with polyamine homeostasis in pancreatic islet cells is not known.

In the previous reports (Hardikar et al. 2003, Gershengorn et al. 2004), human pancreatic PANC-1 cells have been used as a model to study the process of pancreatic islet formation. Following brief trypsin treatment and culturing in a chemically defined serumfree medium (SFM), cells formed islet-like cell aggregates and expressed the functional markers of pancreatic islet cells including insulin and glucagon (Hardikar et al. 2003). In this study, we examined the functional potential of AsPC-1 cells, a human pancreatic adenocarcinoma cell line, and found that these cells can be converted to cells that produce glucagon but not insulin and form an islet-like structure by brief trypsin treatment and subsequent culture in SFM. We also studied the role of AZ1 in converting AsPC-1 cells into the differentiated state and found that the morphological and functional changes were blocked by depletion of AZ1 using siRNA, whereas overexpressing EGFP-AZ1 enhanced glucagon production. AZ1-mediated AsPC-1 cell differentiation was not affected by altering the cellular contents of putrescine and spermidine. Our results suggest that AZ1 plays a key role in converting AsPC-1 cells into glucagon-producing cells and its effect is distinct from the one on polyamine metabolism.

\section{Materials and methods}

\section{Cell culture}

Human pancreatic adenocarcinoma AsPC-1 cells (Dainippon Sumitomo Pharma, Osaka, Japan), PK-1 cells and PK-59 cells (Riken Cell Bank, Tsukuba, Japan) were maintained in 10\% FBS-RPMI 1640. PANC-1 cells (Dainippon Sumitomo Pharma) and MIA paca2 cells (Riken Cell Bank) were maintained in $10 \%$ FBS-DMEM. Cells were plated at a density of $1 \times 10^{6}$ cells/well in six-well culture dishes. To induce differentiation, cells were washed with PBS three times and then treated for $30-60 \mathrm{~s}$ with $0.05 \%(\mathrm{v} / \mathrm{v})$ trypsin/EDTA (GIBCO) at room temperature with care not to detach cells from culture plates. Cells were then cultured in serum-free DMEM/F10 medium containing $17.5 \mathrm{mM}$ glucose and $1 \%$ BSA for the indicated time period without medium change at $37^{\circ} \mathrm{C}$ in a humidified $5 \% \mathrm{CO}_{2}$ atmosphere.

\section{Confocal microscopy}

Cells were fixed with $4 \%$ (v/v) paraformaldehyde (WAKO, Osaka, Japan) for $30 \mathrm{~min}$ at room temperature and then permeabilized with $0.3 \%(\mathrm{v} / \mathrm{v})$ tritonX100. The cells were then treated with $3 \%(\mathrm{w} / \mathrm{v}) \mathrm{BSA}$ in PBS to block the non-specific binding and were stained with anti-glucagon (Sigma) or anti-AZ1 antibodies (gift from Prof. S Matsufuji; Jikei.Med.Univ., Tokyo, Japan). Alexa 488 or Alexa 546-conjugated anti-mouse IgG (Molecular Probes, Eugene, OR, USA) were used as the secondary mAb for staining. The stained cells were analyzed using a confocal laser microscope (Fluoview, FV1000, Olympus, Tokyo, Japan). Images were obtained using a $40 \times$ oil-immersion objective lens (UPlan FL N $40 \times / 1.30$ ). Glucagon production was estimated by measuring the intensity of fluorescent dye in at least 300 cells per culture dish using FV10ASW software (Olympus).

\section{Flow cytometry analysis}

Cultured AsPC-1 cells were dissociated in PBS and single-cell suspensions of AsPC-1 cells were fixed in $4 \%$ paraformaldehyde for $10 \mathrm{~min}$ at $37^{\circ} \mathrm{C}$. Cells were washed twice with FACS buffer (1\% (w/v) FBS, $0.09 \%$ $(w / v) \mathrm{NaN}_{3}$ in PBS) and then incubated with antihuman glucagon $\mathrm{mAb}$ for $24 \mathrm{~h}$ at $4{ }^{\circ} \mathrm{C}$. After washing twice with FACS buffer, cells were stained with Alexa488-conjugated anti-mouse IgG for $30 \mathrm{~min}$ at room temperature. Cells were then passed through an iron mesh $(0.55 \mu \mathrm{m})$ and analyzed on FACSAria (BD Bioscience, San Diego, CA, USA) using the BD FACSDiva software. 


\section{RT-PCR}

Total RNA was isolated from cells using RNA-Bee RNA isolation regent (Wako). Reverse transcription was performed according to the instructions provided with the Takara RNA PCR Kit (AMV version 3.0, Takara, Otsu, Japan). The PCR amplification employed 25-40 cycles with steps at $94{ }^{\circ} \mathrm{C}$ for $2 \mathrm{~min}, 60^{\circ} \mathrm{C}$ for $30 \mathrm{~s}$, and $72{ }^{\circ} \mathrm{C}$ for $1 \mathrm{~min}$ with TaKaRa EX Taq HS. The primers used were as follows: glucagon, forward $5^{\prime}$-aagtatctggactccaggcg- $3^{\prime}$ and reverse $5^{\prime}$-actggtaaaggtcccttcagc- $3^{\prime}$; Pax6, forward $5^{\prime}$-caggaaggagggggagagaa- $3^{\prime}$ and reverse $5^{\prime}$-ttctttgcagcttccgcttc- $3^{\prime}$; PC-2, forward $5^{\prime}$-gtcettgatgcaggtgccatg- $3^{\prime}$ and reverse $5^{\prime}$-actccttcagcaccccttc- $3^{\prime}$; Pdx-1, forward $5^{\prime}$-aagctcacgcgtggaaag- $3^{\prime}$ and reverse $5^{\prime}$-gccgtgagatgtacttgttgaa- $3^{\prime}$; ISL1, forward $5^{\prime}$-gcagccaatgacaaaactaa- $3^{\prime}$ and reverse $5^{\prime}$-ccgtcgtgtctctctggact- $3^{\prime}$; synaptophysin forward $5^{\prime}$-actatgggcagcaaggctac- $3^{\prime}$ and reverse $5^{\prime}$-gtcctcctgggcttcactg-3'; E-cadherin, forward $5^{\prime}$-cctcgacacccgattcaaag- $3^{\prime}$ and reverse $5^{\prime}$-tcccaggcgtagaccaagaa- $3^{\prime} ; \beta$-actin, forward $5^{\prime}$-caaggccaaccgcgagaa- $3^{\prime}$ and reverse $5^{\prime}$-gtccatcacgatgccagtggta- $3^{\prime}$; rat AZ1, forward $5^{\prime}$-gagcaactccaggctgacca- $3^{\prime}$ and reverse $5^{\prime}$-ttcttggctttgagattgtgagacc- $3^{\prime}$. After amplification, $10 \mu \mathrm{l}$ of each reaction mixture was analyzed by $2 \%$ agarose gel electrophoresis, and the products were then visualized by ethidium bromide staining.

\section{Realtime PCR}

cDNA was prepared from the total RNA of AsPC-1 cells with ExScript RT reagent kit (Takara) or PrimeScript RT reagent kit. The quantitative realtime PCR reactions were performed using SYBR Premix Ex Taq (Takara) in a LightCycler (Roche Diagnostics). The primer sequences used were the same as those in RT-PCR analysis. Samples were incubated for the initial denaturation at $95^{\circ} \mathrm{C}$ for $10 \mathrm{~min}$, followed by $40-50$ cycles consisting of three steps at $95{ }^{\circ} \mathrm{C}$ for $10 \mathrm{~s}, 60{ }^{\circ} \mathrm{C}$ for $10 \mathrm{~s}$, and $72{ }^{\circ} \mathrm{C}$ for $10 \mathrm{~s}$. Cycleto-cycle fluorescence emission readings were monitored at $72{ }^{\circ} \mathrm{C}$ at the end of each cycle and analyzed using LightCycler Software (Roche Diagnostics). All quantifications were normalized to $\beta$-actin.

\section{Transfection and stably expression of EGFP-rat AZ1}

An expression vector, pEGFP-rat AZ1, was a gift from Drs Noriyuki Murai and Senya Matsufuji (Jikei. Med.Univ., Tokyo, Japan). Rat AZ1 has an $\sim 85 \%$ homology to human AZ1. It expresses a full-length AZ1 without the frameshift because of the deletion of one thymine nucleotide (Murai et al. 2003). Transfection was carried out with $4.0 \mu \mathrm{g}$ plasmid DNA/well using Lipofectamine 2000. Transfected cells were subjected to antibiotic selection with $500 \mu \mathrm{g} / \mathrm{ml} \mathrm{G} 418$ (Wako) for $24 \mathrm{~h}$. G418-resistant cells were detected two to three weeks. Rat AZ1/pEGFP-expressing cells were cultured with $2 \mu \mathrm{M}$ putrescine.

\section{Small interfering RNA}

The non-silencing control siRNA and AZ1 siRNA were purchased from Qiagen. Cells were transfected with the siRNA $(150 \mathrm{nM})$ in the presence of Lipofectamine 2000 (Invitrogen). After 2 days, cells were induced to differentiate in SFM and further cultured in the presence of the siRNA. Various assays were performed 6 days after the first transfection of siRNA.

\section{Western blot}

Cell extracts were prepared by lysing cells for $30 \mathrm{~min}$ on ice in a lysis buffer containing $1 \%(\mathrm{v} / \mathrm{v})$ NP-40, $0.1 \%$ (v/v) SDS, $0.5 \%(\mathrm{w} / \mathrm{v})$ sodium deoxycholate and one tablet of Complete Mini (Roche Diagnostics). The extracts were centrifuged for $10 \mathrm{~min}$ at $14000 \mathrm{~g}$ at $4{ }^{\circ} \mathrm{C}$, and the supernatant was collected and boiled in SDS sample buffer for $5 \mathrm{~min}$. The sample solution $(100 \mu \mathrm{g}$ protein) was analyzed by SDS-PAGE (10\% gel) and immunoblotted with the polyclonal anti-rat AZ1 antibody followed by a peroxidase-conjugated secondary antibody (Histofine, Nichirei, Japan). Immunoreactions were performed using the ECL Advance western blotting kit (GE Healthcare, Piscataway, NJ, USA) and visualized bands were analyzed on LAS-3000 (Fujifilm, Tokyo, Japan) using Multi Gage V3.0 software.

\section{Measurement of cellular polyamines}

AsPC-1 cells were collected by centrifugation and washed with PBS. For extraction of polyamines, the cells were homogenized on ice in $100 \mu \mathrm{l}$ of $0.1 \mathrm{M} \mathrm{HCl}$, and then $100 \mu \mathrm{l}$ of $0.5 \mathrm{M} \mathrm{HClO}_{4}$ was added. The cell extracts were centrifuged $\left(12000 \mathrm{~g}, 10 \mathrm{~min}, 4^{\circ} \mathrm{C}\right)$, and the supernatant was used for the measurement of putrescine, spermidine and spermine contents. The amount of putrescine, spermidine and spermine was quantitated by mass spectrometric analysis (Samejima et al. 2007). 


\section{Results}

\section{Pancreatic tumor cells can be induced to differentiate into glucagon-producing cells}

Human pancreatic tumor cell lines, AsPC-1, MIA paca2, KP-1, KP-59 and PANC-1 cells, cultured in the growth medium exhibited no functional properties of pancreatic cells including the synthesis of pancreatic hormones, insulin and glucagon. However, when the cells were briefly treated with trypsin and then cultured in a chemically defined medium without serum (SFM), they all formed islet-like clusters and produced pancreatic hormones (Fig. 1). PANC-1, MIA paca2, $\mathrm{KP}-1$ and KP-59 cells produced insulin and glucagon, whereas AsPC-1 cells produced glucagon but not insulin. Our results related to PANC-1 cells were in accord with those reported previously (Hardikar et al. 2003, Gershengorn et al. 2004).

As shown in Fig. 2, AsPC-1 cells cultured in SFM for 3 days stopped growing, formed islet-like cell clusters (the upper panel) and produced glucagon (the lower panel). After 6 days, the size of cluster and the extent of glucagon production were substantially increased. AsPC-1 cells that were not pre-treated with trypsin were not converted to differentiate when cultured in SFM. In addition, those cells that received trypsin treatment but cultured in the growth medium also did not form cell clusters and produced no glucagon. These results indicated that trypsin treatment and the subsequent culture in SFM were required for converting AsPC-1 cells into the differentiated state. The conversion of AsPC-1 cells to glucagon-producing cell clusters was a reversible process since these cells stopped glucagon synthesis and started to disaggregate and grow when SFM was switched to the serumcontaining growth medium.

The percentage of glucagon-producing AsPC-1 cells was determined by the intracellular immunofluorescent staining with the anti-glucagon $\mathrm{mAb}$ and flow cytometric analysis (Fig. 2B). Glucagon-producing cells comprised $\sim 60 \%$ of the entire cultured cell population on day 6 , whereas no glucagon-producing cells were detected on day 0 . In addition, we found that differentiated AsPC-1 cells responded to the step-wise reduction of glucose concentration in the incubation medium by producing the increasing amount of glucagon. Moreover, glucagon production in differentiated AsPC-1 cells was suppressed by insulin treatment. Thus, AsPC-1 cells exhibited the functional properties of normal pancreatic alpha cells in vivo (Rall et al. 1973, Unger 1973).

Pancreatic $\alpha$-cell differentiation is exquisitely regulated by various factors including transcription factor Pax6 (St-Onge et al. 1997), Pdx-1 (Wilson et al. 2003, Jensen 2004) and ISL1 (Wang \& Drucker 1995) as well as PC2 (Vincent et al. 2003), while cadherinmediated cell-cell adhesion is also critical in pancreatic islet differentiation (Dahl et al. 1996, Minami et al. 2008). Accordingly, we examined the expression of these genes during the AsPC-1 cell differentiation by RT-PCR analysis. As shown in Fig. 2C, mRNAs encoding Pax6, PC2 and E-cadherin were undetectable or very low on day 0 but increased markedly after 6 day culture in SFM. On the other hand, $P d x-1$ and ISL1 mRNA were present at the beginning of culture and their levels did not change appreciably after 6 day culture in SFM. Synaptophysin mRNA, a neuroendocrine marker (Egawa et al. 1996, Lukinius et al. 2003),
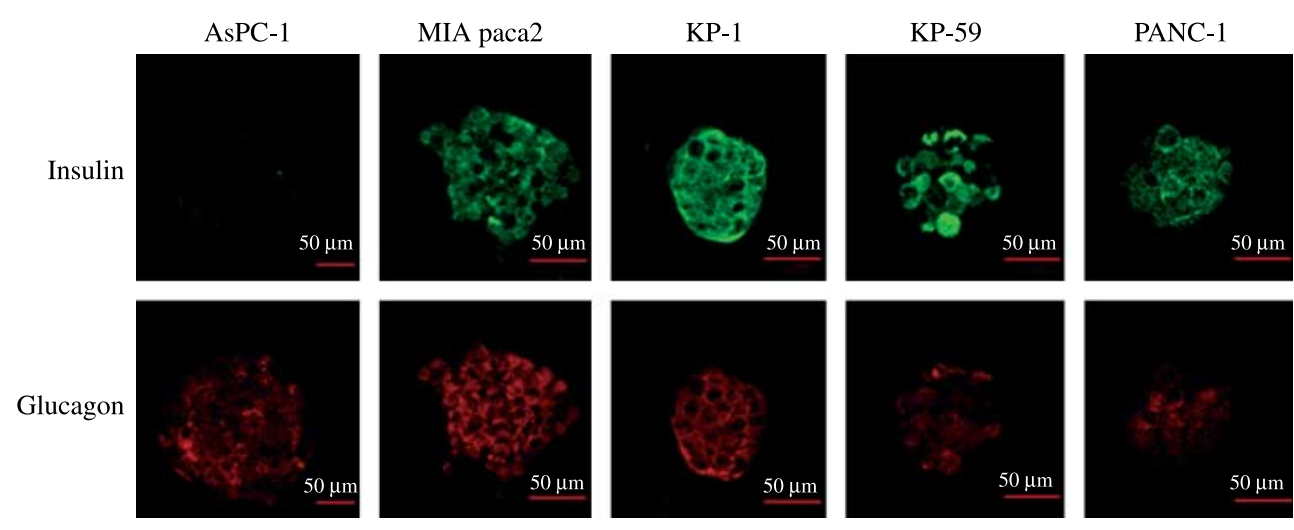

Figure 1 Induction of pancreatic tumor cells to differentiated state. AsPC-1, MIA paca2, KP-1, KP-59 and PANC-1 cells were briefly treated with trypsin and then cultured in SFM for 6 days. Cells were fixed and stained with anti-pig insulin, anti-human glucagons, anti-guinea pig IgG-Alexa 488 and anti-mouse IgG-Alexa 546. The details were described in Materials and methods. Images were analyzed using a confocal laser microscope. Scale bar: $50 \mu \mathrm{m}$. 


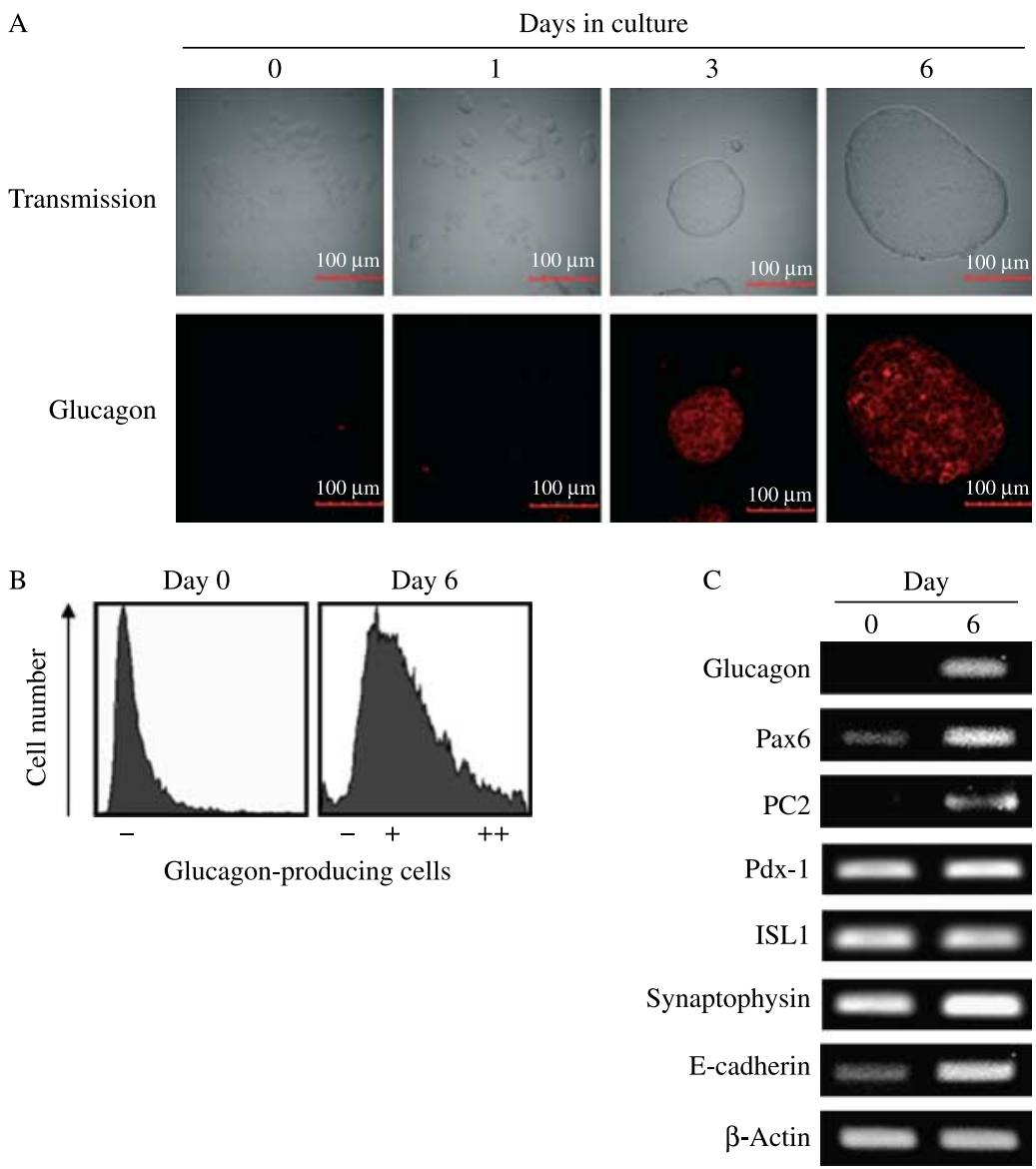

Figure 2 Induction of AsPC-1 cells to differentiated state. (A) Cell morphology and glucagons expression of AsPC-1 cells cultured in SFM. Immunostaining of AsPC-1 cells was carried out on days $0,1,3$, and 6 in culture. Cells were fixed and stained with anti-human glucagons $\mathrm{mAb}$ and anti-mouse IgG-Alexa 546. Images were analyzed using confocal laser microscope. Scale bars: $100 \mathrm{~mm}$.

(B) Analysis of glucagons-producing cell population. Cells were fixed and stained with monoclonal anti-glucagon and anti-mouse IgG-Alexa 488 on day 0 and day 6 in culture. Glucagon-containing cells were detected by flow cytometric analysis. (C) Gene expression in AsPC-1 cells. RT-PCR analysis was performed to examine the expression of gene encoding glucagons Pax6, PC2, PDX1, ISL1, synaptophysin, E-cadherin and $\beta$-actin in cultured cells on day 0 or on day 6 .

was also present on day 0 and increased modestly (1.5-fold) on day 6. The above results demonstrated that AsPC-1 cells could be induced to express the morphological and functional properties of differentiated alpha cell. In the following studies, we used the islet-like cluster formation and glucagon production as the marker of pancreatic tumor cell differentiation.

\section{AZ1 is up-regulated in pancreatic tumor cells during differentiation}

To determine whether AZ1 was involved in AsPC-1 cell differentiation, we first examined the time course of AZ1 production in cells cultured in SFM. Western blot analysis showed that AZ1 was barely detectable on day 0 but its level began to increase on day 1 and increased further on day 3 and day 6 (Fig. 3A).
In addition, we found that the increase in $A Z 1$ mRNA was apparent in differentiated cells but not in undifferentiated cells (data not shown). The temporal patterns of AZ1 and glucagon production indicated that the increase of AZ1 preceded that of glucagon (Figs 2A and 3A).

We performed an immunocytochemical analysis to determine the intracellular localization of AZ1 in nondifferentiated AsPC- 1 cells on day 0 and differentiated cells on day 6 in culture. As shown in Fig. 3B, AZ1 was localized in the cytosol on day 6 , whereas it was in the nucleus on day 0 . The appearance of AZ1 in the cytosol was detected in some cells as early as day 1 in culture (data not shown). These results indicated that AsPC-1 cell differentiation involved the increase of $\mathrm{AZ1}$ protein as well as the change in its localization from the nucleus to the cytosol. 
A

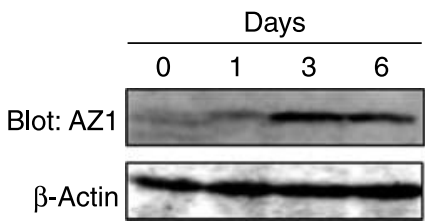

B
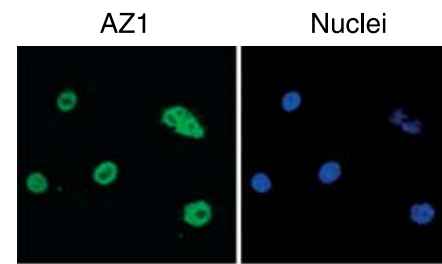

Transmission

Day 6
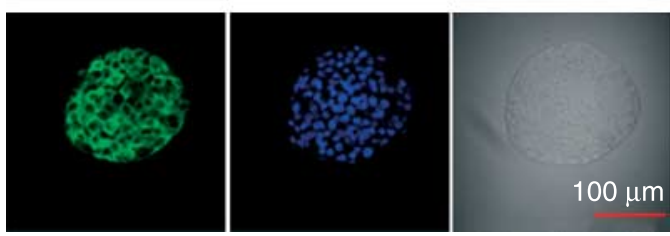

Figure 3 The expression and intracellular localization of antizyme 1 in pancreatic tumor cells. (A) Western blot analysis of AZ1. Whole-cell extracts from AsPC-1 cells on days $0,1,3$, and 6 in culture were analyzed by SDS-PAGE and immunoblotted with polyclonal anti-AZ1 and anti- $\beta$-actin antibodies, as described in the Materials and methods. (B) Intracellular localization of AZ1. Cells were stained with polyclonal and anti-AZ1 and TO-PRO3 (nuclei staining) on day 0 (the upper panel) and day 6 in culture (the lower panel). Images were analyzed using a confocal laser microscope. Scale bars: $40 \mu \mathrm{m}$ (upper) and $100 \mu \mathrm{m}$ (lower).

\section{Inhibition of AZ1 expression by AZ1 siRNA blocks pancreatic tumor cell conversion into glucagon-producing cells}

In order to examine whether AZ1 was required for converting AsPC-1 cells into the differentiated state, we transfected AsPC-1 cells with control or AZ1 specific siRNA 2 days prior to inducting differentiation, and then cells were cultured in SFM in the presence of either control or AZ1 siRNAs for 4 days. The results of western blot analysis indicated that the level of AZ1 in cells treated with AZ1 siRNA was reduced $\sim 85 \%$ when compared with that in cells treated with control siRNA (Fig. 4A). In addition, it was found that cells transfected with AZ1 siRNA formed islet-like cell clusters that were smaller and less organized (Fig. 4B). These cells also contained the lower level of E-cadherin mRNA when compared with cells transfected with control siRNA (Fig. 4D). In addition, the knock-down of AZ1 was associated with the reduction in the amount of Pax6 and glucagon mRNAs that were decreased 85 and $70 \%$ respectively, relative to the corresponding amount in control cells (Fig. 4D). We also examined glucagon production in
AZ1-depleted cells by flow cytometric analysis. As shown in Fig. 4C, those cells expressed the substantially reduced level of glucagon. However, the ability of AZ1-depleted cells to produce glucagon was restored by expressing of EGFP-rat AZ1 in these cells.

As previously reported (Hardikar et al. 2003) and confirmed in this study, PANC-1 cells also expressed glucagon mRNA when briefly treated by trypsin and cultured in SFM. However, when PANC-1 cells were treated with siRNA for AZ1, these cells reduced the expression of glucagon mRNA (Fig. 4E). These results suggested that AZ1 was necessary for converting pancreatic tumor cells into glucagon-producing cells.

\section{Enhancement of glucagon production in differentiated pancreatic tumor cells by constitutive overexpression of AZ1}

We next examined the effect of constitutive overexpression of AZ1 on AsPC-1 cell differentiation. AsPC-1 cells were transfected with expression vectors of EGFP-rat AZ1 or EGFP alone, and EGFP-positive cells were identified by flow cytometric analysis and fluorescence microscopy. The expression level of rat $A Z 1$ in transfected cells was determined by RT-PCR. As shown in Fig. 5A, cells transfected with EGFP-rat AZ1 expressed rat AZI mRNA but cells transfected with EGFP did not. The effect of constitutive overexpression of AZ1 on AsPC-1 cell differentiation was assessed by examining glucagon expression during the 6 days culture in SFM. The RT-PCR analysis showed that the level of glucagon mRNA was dramatically elevated in cells transfected with EGFP-AZ1 when compared with that in EGFP transfected cells (Fig. 5B). In addition, we found by confocal microscopic analysis that glucagon production was markedly increased in EGFP-AZ1-transfected cells when compared with control cells (Fig. 5C). These results indicated that constitutive overexpression of AZ1 enhanced glucagon production in AsPC-1 cells.

\section{Polyamine contents during pancreatic tumor cell differentiation}

AZ1 is known to be a negative regulator of polyamine metabolism (Hayashi et al. 1996, Coffino 2001). It binds to ODC and enhances its degradation by proteasome, thereby inhibiting polyamine biosynthesis. We examined the polyamine contents in AsPC-1 cells during culture in SFM. As shown in Fig. 6A, the content of putrescine decreased progressively in differentiating AsPC-1 cells during 6 days culture. This change was consistent with the observed 
A

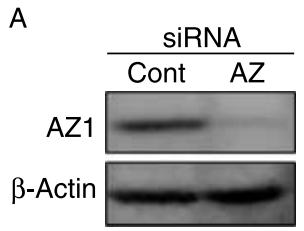

B

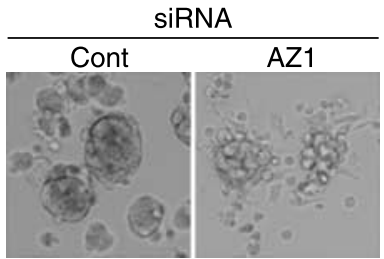

C

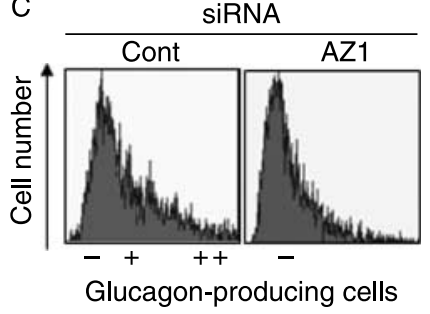

mRNA: $\quad$ SiRNA
Cont AZ1
Glucagon
$\beta$-Actin
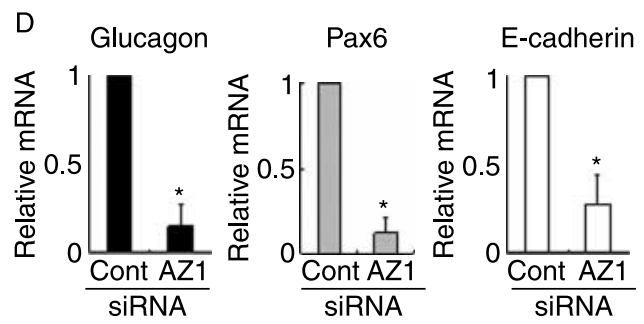

Figure 4 The effect of antizyme 1 siRNA transfection on the differentiation of pancreatic tumor cells. AsPC-1 or PANC-1 cells were first transfected with AZ1 siRNA or control siRNA $(150 \mu \mathrm{m})$ for 2 days and then induced to differentiate in SFM culture medium in the presence of one of the two siRNAs for 4 days. (A) Western blot analysis of AZ1 protein was performed on AsPC-1 cells 6 days after the first transfection with AZ1 siRNA (Cont). Cell lysates were analyzed by SDS-PAGE and immunoblotted with polyclonal anti-AZ1 and anti- $\beta$-actin antibodies. (B) Morphological appearance of cells. AsPC-1 cells transfected with AZ1 siRNA (AZ1) and cells transfected with control siRNA (Cont.) were examined microscopically. Images were taken under the microscope (IX71, Olympus, subject lens $\times 10)$. Scale bars $500 \mu \mathrm{m}$. (C) Analysis of glucagon-producing cells 6 days after transfection with AZ1 siRNA (AZ1) or control siRNA (Cont). Cells were fixed and stained with monoclonal anti-glucagon and anti-mouse IgG-Alexa 488. Intracellular glucagons polypeptides were detected by flow cytometric analysis. (D) Quantification of mRNAs encoding glucagons, Pax6 and E-cadherin in AZ1 siRNA (AZ1) or control siRNS (Cont.) transfected AsPC-1 cells by RT-PCR analysis. The expression level of each gene was normalized with that of $\beta$-actin. Data are given as mean \pm s.D. $(n=3){ }^{\star} P<0.05$. (E) The effect of antizyme 1 reduction on PANC-1 cell differentiation. RT-PCR analysis of glucagons and AZ1 mRNA was performed on PANC-1 cells 6 days after the first transfection with AZ1 siRNA (AZ1) or control siRNA (Cont).

increase in AZ1 in these cells (Fig. 3A). On the other hand, spermidine and spermine contents remained relatively constant.

To examine whether the decrease of putrescine was causally related to the conversion of AsPC-1 cells to the differentiated state, we assessed the effect of raising the intracellular putrescine content by adding exogenous putrescine into culture. As shown in Table 1, the addition of putrescine at the final concentration in the range of 1-10 mM increased its intracellular level in a concentration-dependent manner. However, these putrescine treatments caused no statistically significant difference in glucagon production. These results suggested that the change in putrescine concentration was not important for AsPC-1 cell differentiation.

\section{Discussion}

Previously pancreatic tumor-derived hormone-producing cells were employed as a model to study the pancreatic cell differentiation (Borden et al. 1993). For example, PANC-1 cells were shown to undergo differentiation into hormone-producing cells after stable expression of Pdx-1 and exposure to GLP1 (Hui et al. 2001) or brief trypsin treatment followed by cultivation in SFM (Hardikar et al. 2003, Gershengorn et al. 2004). Studies on these islet cell-model systems provided valuable information for understanding the mechanism of pancreatic cell differentiation. For example, it was shown that PANC-1 cells produced FGF2 that acted as a paracrine chemo-attractant to stimulate clustering of precursor cells, an early step leading to the formation of islet-like cell aggregate (Hardikar et al. 2003). In the present study, we found that other pancreatic tumor cell lines, AsPC-1, MIA paca2, KP-1 and KP-59 cells, all formed islet-like clusters and produced pancreatic hormones following brief trypsin treatment and the subsequent culture in SFM (Fig. 1). We found that AsPC-1 cells were converted to form an islet-like cluster and produce glucagon following brief trypsin treatment and the 

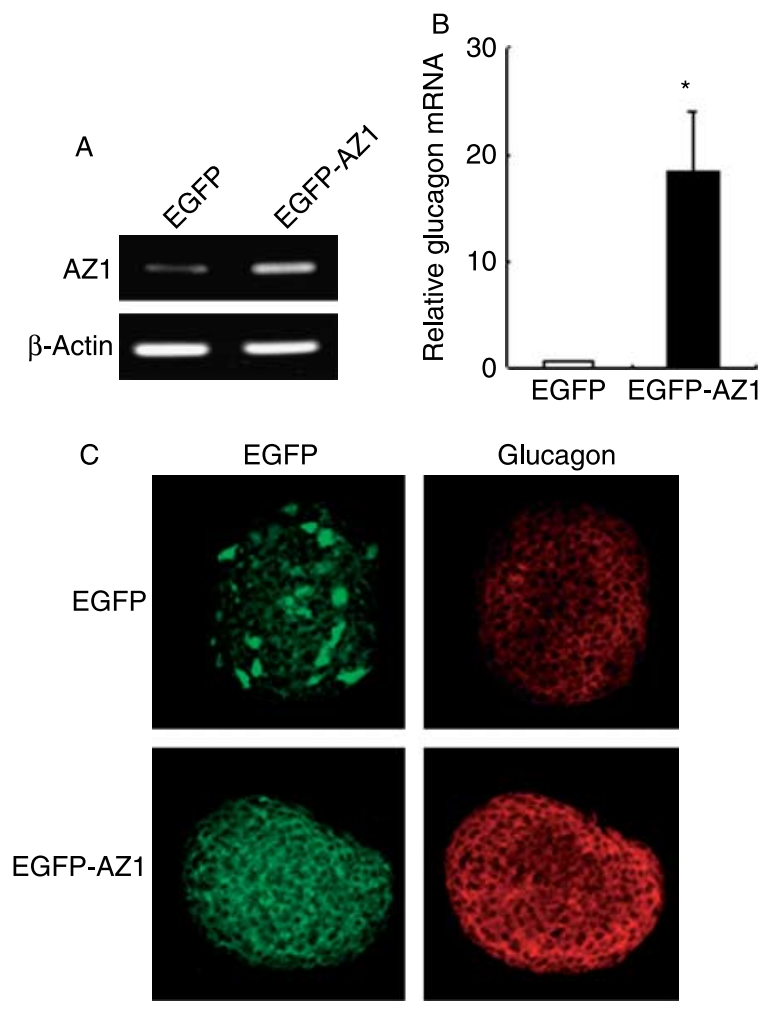

Figure 5 The effect of antizyme 1 overexpression on the differentiation of pancreatic tumor cells. (A) The expression level of AZ1 mRNA in EGFP-AZ1 cells. AZ1 and $\beta$-actin expression were analyzed by RT-PCR using total RNA from AsPC-1 cells stably transfected with pEGFP or pEGFPAZ1 constructs. (B) The expression level of glucagons mRNA in EGFP (control) or EGFP-AZ1 overexpressing AsPC-1 cells. Total RNA from differentiated AsPC-1 cells were analyzed for glucagons mRNA expression by RT-PCR. The expression level of glucagons was normalized relative to that of $\beta$-actin. Data are given as mean \pm s.D. $(n=3){ }^{*} P<0.05$. (C) Analysis of glucagon -producing cells in EGFP and EGFP-AZ1 overexpressing cells after 6 day culture in SFM. EGFP of EGFP-AZ1 overexpressing AsPC-1 cells were fixed and glucagon polypeptides were detected by immunofluorescence staining using anti-human glucagons $\mathrm{mAb}$ and anti-mouse IgG-Alexa 546. Images were analyzed using a confocal laser microscope.

subsequent culture in SFM (Figs 1 and 2A). However, production of insulin was undetectable in AsPC-1 cells. The reason for their inability to produce insulin is not known. In addition, we found that AsPC-1 cells synthesized the increasing amount of glucagon in response to the decreasing glucose concentrations in the culture medium. Moreover, glucagon production by AsPC-1 cells was suppressed by insulin treatment. Earlier studies showed that insulin inhibits transcription of glucagon gene and glucagon synthesis in pancreatic alpha cells in vivo (Maruyama et al. 1984, Philippe 1989). Thus, findings indicated that AsPC-1 cells exhibited several functional and morphological properties of normal pancreatic alpha cells (Rall et al. 1973, Unger 1973).

Our present study as well as the previous work (Hardikar et al. 2003, Gershengorn et al. 2004) indicated that trypsin treatment was the prerequisite for conversion of pancreatic tumor cells into the differentiated state. Recently, the effect of trypsin was shown to be mediated by a protease activated cellsurface receptor, PAR, that enhances cell aggregation (Wei et al. 2006). Since AsPC-1 cells strongly expressed PAR (Ohta et al. 2003), it was possible that the induction of AsPC-1 cell differentiation was triggered by the activation of PAR. After trypsin treatment, AsPC-1 cells cultured in SFM formed an
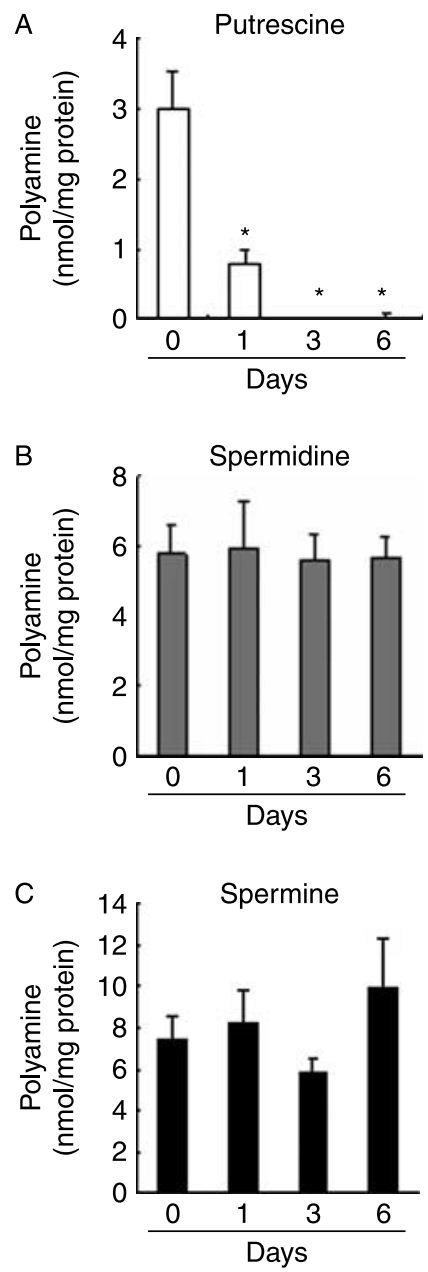

Figure 6 The change in the polyamine contents and the effect of putrescine during the differentiation of pancreatic tumor cells. Polyamine contents in cultured AsPC-1 cells. Cells were cultured for $0,1,3$, and 6 days in SFM and the level of putrescine, spermidine and spermine contents was determined by mass spectrometric analysis as described in the Materials and methods $(n=3){ }^{*} P<0.001$. 
Table 1 The effect of putrescine on glucagon production. AsPC-1 cells were cultured for 6 days in serum-free medium (SFM) in the presence of $0,1,3$ and $10 \mathrm{mM}$ putrescine. Cells were fixed with $4 \%$ paraformaldehyde, and then stained with anti-glucagon $\mathrm{mAb}$ and anti-mouse IgG-Alexa 546. Glucagon production was measured by FV10-ASW software (means \pm S.D.; $n=3$ dishes) as described in the Materials and methods. The level of putrescine content was determined by mass spectrometric analysis (means \pm s.D.; $n=3$ dishes)

\begin{tabular}{lcc}
\hline $\begin{array}{l}\text { Concentration of } \\
\text { putrescine in } \\
\text { culture }\end{array}$ & $\begin{array}{l}\text { Intracellular } \\
\text { putrescine } \\
\text { (nmol/mg protein) }\end{array}$ & $\begin{array}{l}\text { Glucagon } \\
\text { production } \\
\text { (unit/300 cells) }\end{array}$ \\
\hline 0 & $0.8 \pm 0.4$ & $1681 \pm 447$ \\
1 & $3.3 \pm 0.9$ & $2064 \pm 418$ \\
3 & $10.0 \pm 0.3$ & $1545 \pm 185$ \\
10 & $25.5 \pm 0.6$ & $1196 \pm 179$ \\
\hline
\end{tabular}

islet-like cluster and increased the expression of E-cadherin (Fig. 2D) and $\beta$-catenin mRNA (data not shown) that were involved in cell-cell adhesion. Inhibition of the functional activities of E-cadherin and catenins blocked the formation of pancreatic $\beta$-cells (Dahl et al. 1996, Minami et al. 2008). In this study, we found that single AsPC-1 cell that did not form the cluster produced no glucagon (data not shown), whereas glucagon production was prominent among cluster-forming cells. Thus, it appears that the functional and morphological differentiations of AsPC-1 cells are coupled.

We found that the cultivation of AsPC-1 cells in SFM is another prerequisite for converting cells to the differentiated state. Under these conditions cells stopped growing and remained in the G1 phase of cell cycle, which may provide the environment suitable for cell differentiation to take place. In addition, serum starvation may alter the pattern of gene expression that may favor the induction of differentiated properties. Serum starvation culture was used to prepare nuclei for transplantation to make cloned animals (Campbell et al. 1996, Wilmut et al. 1997).

The model of glucagon-producing $\alpha$-cell differentiation was relatively scarce. In this study, we used AsPC-1 cells as a model to study the regulation of glucagon-producing $\alpha$-cell differentiation. Several lines of evidence indicated that AZ1 was required for AsPC-1 cell differentiation. Thus, depletion of AZ1 expression using an AZ1-specific siRNA inhibited the formation of cellclusters and expression of genes such as glucagon, Pax6 and E-cadherin in AsPC-1 cells (Fig. 4D). We also showed that the number of glucagon-producing cells and glucagon production were increased by overexpression of AZ1. Furthermore, the data shown in Fig. $3 \mathrm{~A}$ indicated that the levels of AZ1 both mRNA and protein were increased during AsPC-1 cell differentiation, suggesting that the increase of AZ1 protein occurred, at least in part, through transcriptional regulation. The expression of glucagon mRNA in PANC-1 cells was also inhibited by treatment of AZ1 siRNA (Fig. 4E). These results indicated that transcriptional up-regulation of AZ1 is the key event in conversion of pancreatic tumor cells into the differentiated state.

The previous report showed that AZ1 is primarily localized in the nucleus where it transports ODC from the cytosol for degradation by nuclear proteasome (Gritli-Linde et al. 2001, Murai et al. 2003, Schipper et al. 2004). By contrast, we found that AZ1 was mainly localized in the cytosol during conversion of AsPC-1 cells to the differentiated state (Fig. 3B). These findings suggested that the site of AZ1 action is limited in the cytoplasm wherein it may interact with some proteins involved in regulation of $\alpha$-cell differentiation. Future work is required to identify the target molecules of AZ1 to promote AsPC-1 cell differentiation. It was of interest to note that sex-lethal and cyclin B acting downstream of the Hedgehog signal were the target of Drosophila gutfeeling, the homologue of AZ1 (Vied et al. 2003).

Earlier studies demonstrated that AZ1 serves as a negative regulator of polyamine biosynthesis by binding to ODC and facilitating its degradation (Hayashi et al. 1996, Coffino 2001). Our data in Fig. 6 showed that the intracellular putrescine content was decreased during AsPC-1 cell differentiation when the AZ1 level increased. However, AsPC-1 cell differentiation was not affected by raising the intracellular level of putrescine by exogenously adding putrescine (Table 1). These results indicated that the decrease in putrescine was not important for the AZ1mediated conversion of AsPC-1 cells, and suggested that the effect of AZ1 was separate from the one involved in inhibition of polyamine biosynthesis.

\section{Declaration of interest}

The authors declare that there is no conflict of interest that could be perceived as prejudicing the impartiality of the research reported.

\section{Funding}

This work was supported by MEXT-HAITEKU and the grant from Musashino Joshi-Gakuen Foundation.

\section{Acknowledgements}

We thank Drs Noriyuki Murai, Makiko Ohkido and Senya Matsufuji, Jikei Medical University, Tokyo, Japan for the gift of pEGFP-rat AZ1 and their helpful discussion. 


\section{References}

Andersen F, Heller R, Petersen H, Jensen J, Madsen O \& Serup P 1999 Pax6 and Cdx2/3 form a functional complex on the rat glucagon gene promoter G1-element. FEBS Letters 445 306-310.

Artner I, Le Lay J, Hang Y, Elghazi L, Schisler J, Henderson E, Sosa-Pineda B \& Stein R 2006 MafB: an activator of the glucagon gene expressed in developing islet alpha- and beta-cells. Diabetes 55 297-304.

Borden E, Lotan R, Levens D, Young C \& Waxman S 1993 Differentiation therapy of cancer: laboratory and clinical investigations. Cancer Research 53 4109-4115.

Campbell K, McWhir J, Ritchie W \& Wilmut I 1996 Sheep cloned by nuclear transfer from a cultured cell line. Nature 380 64-66.

Coffino P 2001 Regulation of cellular polyamines by antizyme. Nature Reviews. Molecular Cell Biology 2 188-194.

Dahl U, Sjødin A \& Semb H 1996 Cadherins regulate aggregation of pancreatic beta-cells in vivo. Development 122 2895-2902.

Egawa N, Maillet B, VanDamme B, De Grève J \& Klöppel G 1996 Differentiation of pancreatic carcinoma induced by retinoic acid or sodium butyrate: a morphological and molecular analysis of four cell lines. Virchows Archiv 429 59-68.

Gershengorn M, Hardikar A, Wei C, Geras-Raaka E, Marcus-Samuels B \& Raaka B 2004 Epithelial-tomesenchymal transition generates proliferative human islet precursor cells. Science 306 2261-2264.

Gosmain Y, Avril I, Mamin A \& Philippe J 2007 Pax-6 and c-Maf functionally interact with the alpha-cell-specific DNA element $\mathrm{G} 1$ in vivo to promote glucagon gene expression. Journal of Biological Chemistry 282 35024-35034.

Gritli-Linde A, Nilsson J, Bohlooly YM, Heby O \& Linde A 2001 Nuclear translocation of antizyme and expression of ornithine decarboxylase and antizyme are developmentally regulated. Developmental Dynamics 220 259-275.

Gruendler C, Lin Y, Farley J \& Wang T 2001 Proteasomal degradation of Smad1 induced by bone morphogenetic proteins. Journal of Biological Chemistry 276 46533-46543.

Hardikar AA, Marcus-Samuels B, Geras-Raaka E, Raaka BM \& Gershengorn MC 2003 Human pancreatic precursor cells secrete FGF2 to stimulate clustering into hormoneexpressing islet-like cell aggregates. PNAS $\mathbf{1 0 0}$ 7117-7122.

Hayashi S, Murakami Y \& Matsufuji S 1996 Ornithine decarboxylase antizyme: a novel type of regulatory protein. Trends in Biochemical Sciences 21 27-30.

Hougaard D, Nielsen J \& Larsson L 1986 Localization and biosynthesis of polyamines in insulin-producing cells.

Biochemical Journal 238 43-47.

Hui H, Wright C \& Perfetti R 2001 Glucagon-like peptide 1 induces differentiation of islet duodenal homeobox-1-positive pancreatic ductal cells into insulin-secreting cells. Diabetes 50 785-796.
Hussain M, Miller C \& Habener J 2002 Brn-4 transcription factor expression targeted to the early developing mouse pancreas induces ectopic glucagon gene expression in insulin-producing beta cells. Journal of Biological Chemistry 277 16028-16032.

Ivanov IP, Gesteland RF \& Atkins JF 2000 Antizyme expression: a subversion of triplet decoding, which is remarkably conserved by evolution, is a sensor for an autoregulatory circuit. Nucleic Acids Research 28 3185-3196.

Jensen J 2004 Gene regulatory factors in pancreatic development. Developmental Dynamics 229 176-200.

Lee C, Sund N, Behr R, Herrera P \& Kaestner K 2005 Foxa2 is required for the differentiation of pancreatic alpha-cells. Developmental Biology 278 484-495.

Lim S \& Gopalan G 2007 Antizyme1 mediates AURKAIP1dependent degradation of Aurora-A. Oncogene 26 6593-6603.

Lin Y, Martin J, Gruendler C, Farley J, Meng X, Li B, Lechleider R, Huff C, Kim R, Grasser W et al. 2002 A novel link between the proteasome pathway and the signal transduction pathway of the bone morphogenetic proteins (BMPs). BMC Cell Biology 315.

Lukinius A, Stridsberg M \& Wilander E 2003 Cellular expression and specific intragranular localization of chromogranin A, chromogranin B, and synaptophysin during ontogeny of pancreatic islet cells: an ultrastructural study. Pancreas 27 38-46.

Maruyama H, Hisatomi A, Orci L, Grodsky G \& Unger R 1984 Insulin within islets is a physiologic glucagon release inhibitor. Journal of Clinical Investigation $\mathbf{7 4}$ 2296-2299.

Matsufuji S, Matsufuji T, Miyazaki Y, Murakami Y, Atkins JF, Gesteland RF \& Hayashi S 1995 Autoregulatory frameshifting in decoding mammalian ornithine decarboxylase antizyme. Cell 80 51-60.

Minami K, Okano H, Okumachi A \& Seino S 2008 Role of cadherin-mediated cell-cell adhesion in pancreatic exocrine-to-endocrine transdifferentiation. Journal of Biological Chemistry 283 13753-13761.

Murai N, Murakami Y \& Matsufuji S 2003 Identification of nuclear export signals in antizyme-1. Journal of Biological Chemistry 278 44791-44798.

Newman R, Mobascher A, Mangold U, Koike C, Diah S, Schmidt M, Finley D \& Zetter B 2004 Antizyme targets cyclin D1 for degradation. A novel mechanism for cell growth repression. Journal of Biological Chemistry 279 41504-41511.

Ohta T, Shimizu K, Yi S, Takamura H, Amaya K, Kitagawa H, Kayahara M, Ninomiya I, Fushida S, Fujimura T et al. 2003 Protease-activated receptor-2 expression and the role of trypsin in cell proliferation in human pancreatic cancers. International Journal of Oncology 23 61-66.

Pegg A \& McCann P 1982 Polyamine metabolism and function. American Journal of Physiology 243 C212-C221. 
Philippe J 1989 Glucagon gene transcription is negatively regulated by insulin in a hamster islet cell line. Journal of Clinical Investigation 84 672-677.

Planque N, Leconte L, Coquelle F, Benkhelifa S, Martin P, Felder-Schmittbuhl M \& Saule S 2001 Interaction of Maf transcription factors with Pax -6 results in synergistic activation of the glucagon promoter. Journal of Biological Chemistry 276 35751-35760.

Rall L, Pictet R, Williams R \& Rutter W 1973 Early differentiation of glucagon-producing cells in embryonic pancreas: a possible developmental role for glucagon. PNAS 70 3478-3482.

Ritz-Laser B, Estreicher A, Klages N, Saule S \& Philippe J 1999 Pax-6 and Cdx-2/3 interact to activate glucagon gene expression on the G1 control element. Journal of Biological Chemistry 274 4124-4132.

Samejima K, Otani M, Murakami Y, Oka T, Kasai M, Tsumoto H \& Kohda K 2007 Electrospray ionization and time-of-flight mass spectrometric method for simultaneous determination of spermidine and spermine. Biological \& Pharmaceutical Bulletin 30 1943-1946.

Schipper R, Cuijpers V, De Groot L, Thio M \& Verhofstad A 2004 Intracellular localization of ornithine decarboxylase and its regulatory protein, antizyme-1. Journal of Histochemistry and Cytochemistry 52 1259-1266.

St-Onge L, Sosa-Pineda B, Chowdhury K, Mansouri A \& Gruss P 1997 Pax6 is required for differentiation of glucagon-producing alpha-cells in mouse pancreas. Nature 387 406-409.

Tabor C \& Tabor H 1984 Polyamines. Annual Review of Biochemistry 53 749-790.

Unger R 1973 Normal and abnormal alpha cell function. Annual Review of Medicine 24 303-308.
Vied C, Halachmi N, Salzberg A \& Horabin J 2003 Antizyme is a target of sex-lethal in the Drosophila germline and appears to act downstream of hedgehog to regulate sex-lethal and cyclin B. Developmental Biology 253 214-229.

Vincent M, Guz Y, Rozenberg M, Webb G, Furuta M, Steiner D \& Teitelman G 2003 Abrogation of protein convertase 2 activity results in delayed islet cell differentiation and maturation, increased alpha-cell proliferation, and islet neogenesis. Endocrinology 144 4061-4069.

Wang M \& Drucker D 1995 The LIM domain homeobox gene isl-1 is a positive regulator of islet cell-specific proglucagon gene transcription. Journal of Biological Chemistry 270 12646-12652.

Wei C, Geras-Raaka E, Marcus-Samuels B, Oron Y \& Gershengorn MC 2006 Trypsin and thrombin accelerate aggregation of human endocrine pancreas precursor cells. Journal of Cell Physiology 206 322-328.

Welsh N \& Sjöholm A 1988 Polyamines and insulin production in isolated mouse pancreatic islets. Biochemical Journal 252 701-707.

Wilmut I, Schnieke A, McWhir J, Kind A \& Campbell K 1997 Viable offspring derived from fetal and adult mammalian cells. Nature 385 810-813.

Wilson M, Scheel D \& German M 2003 Gene expression cascades in pancreatic development. Mechanisms of Development 120 65-80.

Xu X, Dai K \& Tang T 2003 The role of Smads and related transcription factors in the signal transduction of bone morphogenetic protein inducing bone formation. Zhongguo Xiu Fu Chong Jian Wai Ke Za Zhi 17 359-362. 